11. Patients with bronchial asthma and chronic nicotinic intoxication during pregnancy / O.B. Prikhodko, A.S. Zenkina, A.F. Babtseva, E.B. Romantsova, E.I. Smorodina, I.V. Kostrova, S.A. Goryacheva // Amur Medical Journal. Blagoveshchensk, 2016. V. 1. № 13. P. 49-51.

12. The clinical course of asthma in pregnant smokers / A.S. Zenkina, O.B. Prikhodko, A.F. Babtseva, E.B. Romantsova // Materials of the VI congress of pulmonologists of Siberia and Far East. Blagoveshchensk, 2015. P.36-39.

UDC 616.248-084:618.2-06 DOI 10.22448/AMJ.2017.3.148-149

\title{
PECULIARITIES OF PLACENTA STRUCTURE IN PATIENTS WITH BRONCHIAL ASTHMA DEPENDING ON THE COURSE OF THE DISEASE DURING PREGNANCY
}

\section{Zenkina A.S., Prikhodko O.B., Romantsova E.B., Kostrova I.V.}

Amur state medical academy, Blagoveshchensk, Russian Federation

Abstracts. Thisarticleanalyzesthemorphologicalfeaturesoftheplacenta ofwomende-pendingontheseverityand nature of thecourseofbronchialasthmaincombination with thepa-thology of pregnancy. Therewasexamination of the pathologicaleffectoftheplacentalcomplexonthecourseofpregnancyandtheprocessoffetaladaptation in patientswith bronchialasthma.

Key words: bronchial asthma, pregnancy, placental insufficiency

Bronchial asthma occupies a leading place in the structure of respiratory diseases in pregnant women $(8.4 \%-13.9 \%)$, which is the reason for the growing interest in this problem throughout the world. The development of placental insufficiency is associated with a violation of maternal hemo-dynamics, which is facilitated by a complicated course of pregnancy and extragenital pathology, including bronchial asthma (BA). Placental insufficiency (PN) is a complex of symptoms that occurs with many complications of pregnancy, indicating the inhibition of the gestational dominant. One of the leading links in the pathogenesis of PN is the disruption of adaptation mechanisms in the moth-er-placenta-fetus system.

According to the literature, women suffering from asthma have a risk of having children with hypotrophy, asphyxia, neurological disorders, congenital malformations, especially in severe BAA number of studies have shown that the course of pregnancy in $A D$ can be complicated by tox-icosis (up to $37 \%$ ), gestosis (up to $43 \%$ ), threat of interruption (up to 26\%), chronic placental insuf-ficiency (CPI) (up to 29\%), premature birth (up to 19\%) [1].

Material and methods. An analysis of the morphological study of the placenta in 42 pa-tients with asthma of different severity was carried out. Group I comprised 22 patients with asthma with exacerbation of the disease during gestation (with uncontrolled course of asthma), group II - 20 patients without exacerbations (partially or completely controlled by asthma), group III - 26 pregnant women without bronchopulmonary pathology (control group). In $57 \%$ of cases there was placental insufficiency, while in $17 \%$ - sub- and decompensated, in $8 \%$ of cases there was a viola-tion of maturation of the placenta. Presented data indicate that placental insufficiency in patients with asthma $(p<0.01)$, especially in uncontrolled flow, was developing more often than in the com-parison group $(p<0.001)$.

Results and discussion. In patients with asthma, in contrast to the comparison group $(p<0.01)$, the pathological immaturity of the placenta was noted more often, which predetermined the unfavorable prognosis for the newborn. All cases of delayed and accelerated maturation of the pla-centa were observed in patients with moderate and severe course of uncontrolled asthma. In 2 out of 10 cases of immaturity of the placenta (among patients with asthma) there was observed dissoci-ated maturation, which is formed as a result of dyschronosis in the formation of villi and lagging behind the development of their capillary channel, which indicates a poor pregnancy in the II - III trimesters of pregnancy.

In the placenta of women of all groups, circulatory changes were more frequent $(p<0.01)$, less often - dystrophic and inflammatory. In patients with asthma in placentas were dominating cir-culatory changes, at the same time combining with inflammatory and dystrophic only in the uncon-trolled course of the disease - in 10 cases. In the ll group of patients, the frequency of circulatory and dystrophic conditions of the placenta was approaching the parameters of the comparison group.

In patients with exacerbations of asthma during gestation, dystrophic changes in the placenta were ominating 1.3 times more often than in the comparison group, which occur when the autoregu-lation of cells and the function of transport systems, are often responsible for intrauterine dystrophy of the placenta. Large number of villi with dystrophic changes in the stroma identified in the mor-phological study contributes to reduced permeability of the placenta, hypoxia of the fetus, metabol-ic, hypotrophic disorders, the appearance of pulmonary diastreme stress syndrome.

Circulatory disorders that characterize the change in blood circulation in the placenta (the presence of pseudoinfarctions, blood flow disorders - stasis, hemorrhages, extensive subbasal in-farcts, necrosis of villi), disorders of utero-placental and placental-fetal blood flow were observed in the placenta in patients with asthma, 1.2 times more often , than in the control group. In the group of people with exacerbation of asthma during gestation, the difference with the comparison group is slightly higher, 1.4 times. Disorders of blood circulation in the placenta, changes in circulation pro-long the process of adaptation of the fetus, contribute to the development of the hypoxic state and the appearance of dystrophic, inflammatory processes. Obtained data put forward focal disturb-ances of circulation in the placenta, especially in case of exacerbation of asthma - hemorrhages and thromboses, infarcts, necrosis, collapse of the intervorsity space, uneven filling of the villi and their vascularization, stasis that promote the development of intrauterine hypoxia of the fetus.

Among inflammatory changes contributing to the development of hypoxic state, in more than $1 / 2$ cases, basal decidu- 
itis, intervilusitis, and vilusitis, indicating a violation of uteroplacental blood circulation. Less often there was a membranitis, deciduitis, mainly in the group with exacerba-tion of asthma during gestation ( $p>0.05)$. In general, inflammatory conditions of the placenta in pa-tients of the I group were noted more often than in II $(p<0.01)$, especially with non-allergic and mixed forms of asthma $(r=0.72, p<0.01)$, chronic diseases of ENT organs $(r=0.54, p<0.05)$.

It should be noted that such pathological reactions as hemorrhages, thromboses, infarcts and necrosis of villi have met with a greater frequency in the placenta of patients with asthma than in the comparison group, while in group II it is 2 times less. Circulatory disorders were more often ob-served in the placenta in patients with BA of group I. Along with this, the nasal angiomatosis and syncytial kidneys more common in group II testified to a higher compensatory potential for the pla-centa of patients with controlled asthma.

Conclusions. Thus, the study of the placenta in patients with allergic diseases is of particular interest, since on the one hand the placenta is a reliable barrier, an immunocompetent organ that de-termines the natural mechanism of fetal protection and the normal course of pregnancy, and on the other, it is a target organ in which, immunological changes are releasing.

\section{References}

1. Dynamics of mild persistent bronchial asthma course in pregnant women / A.F. Babtseva, O.B. Prikhodko, E.B. Romantsova, Y.S. Landishev, I.V. Kostrova // Breath physiology and patholo-gy Journal, 2012. Issue 46. P. 39-43.

2. Features of social-economic status in pregnant women with bronchial asthma / T.A. Luchnikova, O.B. Prikhodko // Breath physiology and pathology Journal, Blagoveshchensk, 2015. Issue 56. P. 78-82.

3. Evolution clinical and epidemiological course of bronchial asthma in during pregnancy / T.A. Luchnikova, O.B. Prikhodko, A.F. Babtseva, E.B. Romantsova, M.V. Pogrebnaya, E.I. Smorodina // The 11th Sino-Russia forum of biomedical and pharmaceutical science: the confer-ence proceedings. Harbin, 2014. P.166-167.

4. Prikhodko O.B. Clinical and functional features of bronchial and lung systems and neuro-vegetative regulation in patient with asthma in during pregnancy and their effects on offspring. abstract of thesis...doctor of medical sciences. Blagoveshchensk, 2010. $44 \mathrm{p}$.

5. Prikhodko O.B. Neurovegetative regulation and hemodynamics of pregnant women with bron-chial asthma // Allergology and Immunology Journal. 2009. V. 10, № 1. P. 84.

6. The role of controlled asthma in the development of complications of pregnancy and influence on the health of newborns / O.B. Prikhodko, A.F. Babtseva, E.B. Romantsova //International journal on immunorehabilitation. 2009. V. 11, № 1. P. 38-39.

7. Influence of clinical and functional features of bronchopulmonary system at pregnant women with asthma on the condition of child / O.B. Prikhodko, A.F. Babtseva, E.B. Romantsova //International journal on immunorehabilitation. 2010 . V. 12 , № 2. P.114a.

8. Changes of the placenta in patients with bronchial asthma depending on the level of disease con-trol / O.B. Prikhodko, A.S. Zenkina, I.V., Kostrova, S.A. Goryacheva, E.I. Smorodina // Aller-gology and Immunology Journal. 2016. Vol. 17, №2. P. 134.

9. The lack of asthma control during pregnancy as a predictor of perinatal complications / O.B. Prikhodko, A.F. Babtseva, E.B. Romantsova, Y.S. Landyshev, T.A. Luchnikova, E.I. Smorodi-na, I.V. Kostrova //Allergology and Immunology Journal. 2013. V. 14, № 3. P.188-189.

10. Morphological characteristics placenta in bronchial asthma patients in the control of its accord-ing to treatment. / O.B. Prikhodko, A.F. Babtseva, E.B. Romantsova, et al. // The 8th Russia - China Pharmaceutical Forum "Modern problems of nanopharmacology». - Blagoveshchensk, 2011. P. 81-82.

11. Patients with bronchial asthma and chronic nicotinic intoxication during pregnancy / O.B. Prikhodko, A.S. Zenkina, A.F. Babtseva, E.B. Romantsova, E.I. Smorodina, I.V. Kostrova, S.A. Goryacheva // Amur Medical Journal. Blagoveshchensk, 2016. V. 1. № 13. P. 49-51.

12. The clinical course of asthma in pregnant smokers / A.S. Zenkina, O.B. Prikhodko, A.F. Bab-tseva, E.B. Romantsova // Materials of the VI congress of pulmonologists of Siberia and Far East. Blagoveshchensk, 2015. P.36-39.

\section{UDC 378 DOI 10.22448/AMJ.2017.3.149-151 THE PROBLEM OF CIVILIZATION IN THE SYSTEM OF UNIVERSAL EDUCATION}

\section{E. N. Gordienko}

\section{Of the "Amur state medical Academy", Department of histology and biology, Blagoveshchensk, Russia}

Summary. Settle the main goal of General education designed to combine in the twenty-first century, countries, peoples, religion, in the common positive development. They include as a mandatory imperative, the concept of "civilization". However, contrary to the hopes of mankind in the new Millennium has moved many of the problems of the triad "Nature - Consciousness - People", denying a key idea - the civilized world! In this regard, prior to teaching, all teachers, regardless of seniority and teaching experience, there is a need for: on the basis of knowledge of problems, including global, forming life position of the young man - "for positive development, for civilized world, in which reigns the MIND"!

Key words: civilization, criteria anticivilian of world development, aims and objects of education.

The strategic goal in this regard is the creation of scientific foundations of Bioethics - moral concept of Life. Only on its basis with the participation of natural Sciences and Humanities, will open a new ideology of generations: "do Not harm!", "Help!", "Know thyself!" "Create yourself!". It is the future ideology of humanity, the self, poster- 